\title{
The Use of Information and Communication Technology (ICT) in Agricultural and Rural Transformation in Delta State.
}

\author{
O. Ugboh (PhD) \& E.U. Tibi (PhD)
}

\begin{abstract}
Agricultural and rural transformations are key development strategies for Delta State in particular and Nigeria in general. This is because Nigeria has a vast rural community with broadly unsophisticated agricultural base. Therefore, to transform Agriculture and rural development from this state of un-sophistication and backwardness, there is the need to meet up with farmers production needs which vary from one locality to another. This implies that if the rural community must not be left behind in the effort to creating a knowledgeable society in which ICT becomes the key to socio-economic development, there is the need now, to bridge the gap in the digital divide in information technology aimed at building capacity of rural dwellers to enhance Agricultural and rural transformation. The study examined the use of information and communication technology in Agricultural and rural transformation in Delta State. The stratified sampling technique was used in selecting the respondents who are made up of extension agents of the Agricultural Development programme (ADP), Agricultural staff of the state ministry of Agriculture and those of the Agricultural unit of sampled local government councils. All the respondents from the three Agricultural zones of the state were studied, using questionnaire designed to elicit information. Descriptive statistics such as frequencies, means and percentages were adopted in analysing data.
\end{abstract}


Finding revealed that ICT is a veritable tool and requirement for agricultural and rural transformation even though it is not widely accessed by farmers in these communities. It was recommended that information communication technology facilities be made available in most rural localities in the state such as internet facilities, overhead projector, video cameras, etc and the Agricultural extension staff should be properly trained in this area to be able to train farmers using ICT facilities.

\section{Introduction}

Rural and agricultural transformation programmes are key development strategies for countries with a large and broadly unsophisticated agricultural base. Nigeria has adopted various strategies which include agricultural extension and rural development programmes. How ever, most, if not all of the strategies failed in Nigeria. This is justified by the fact that agricultural extension is getting weaker in Nigeria as a result of under-funding, neglect and mismanagement by successive administration, combined with the ineffective and expensive system which has resulted in a situation where it is difficult for agriculture in Nigeria to grow further.( Oladosu, 2005).

In fact, what we see today about rural and agricultural transformation programmes and projects, can best be described as dead and ineffective institutions, structures and policies which have had more diminutive effects on agricultural and rural transformation than the hypersensitivity which the sector is expected to feel.

Arising from the picture painted above; there is the need for the re-organisation of rural and agricultural transformation strategies from their present levels of 
relegation to a foremost position in the scheme of things in Nigeria. Adedoyin (2004) claims that it is widely known and recognised that sustained high level of agricultural and rural transformation programmes to ensure food self-sufficiency cannot be attained without effective strategies which requires the application of Information Communication Technology (ICT).

\section{Use of ICT in Agricultural and Rural Transformation}

Early last century, there was an explosion of scientific development. Advances in scientific discoveries, communication technologies and educational practices invariably facilitated procedures in effecting the transfer of messages, knowledge and instruction required by rural farmers necessary for agricultural and rural transformation.

More recently in the last 50 years, contemporary discoveries, inventions and developments in electronics has given rise to a new generation of electronic audio-visual aids which are necessary for the transformation of the agricultural and the rural sectors (Adebayo, 1997). Some of these are not only computers and televisions sets themselves but computer based and television based e.g. video text, broadcast teletext, the slow scan television, the communication satellite and the intelligent telephones. These aids may be of little use at farm level in many parts of the world today, it provides the opportunity to maintain networks of information flow amongst researchers, development experts and policy makers.

In order to attain the required growth in the rural and agricultural sector, the rural community must not be left behind in the effort in creating a knowledgeable society in which ICT becomes the key to socio-economic development (Tap Bin Sallah, 2004). There is the need to bridge the digital 
divide in information technology aimed at building the capacity of the rural dwellers. In most developing countries like Nigeria, opportunities offered by ICT can be exploited for enhancing the income of farmers and other rural dwellers through improved knowledge about new ways of farming, fishing, animal production and home management. Marketing information is also made easy for producers to be linked directly with consumers. This will enhance better pricing. Apart from these benefits, it also enhances family living and information on alternative employments and recreation. (Tap Bin Sallah 2004). This applications, reinforces the poor policy implementation strategies adopted in Africa, since it is widely known that the availability of timely relevant and accurate information is known to make the difference between the success and failure of projects, between profit and loss for business organisations as well as victory and defeat for nations. So pervasive is the role of information presently that the world is generally described as being in the information age (Akinde, and Adagunodo 2001). From the foregoing, it can be seen that the study is set to assess the use of ICT in agriculture and rural transformation in Delta State. The necessity for improving the knowledge base of the rural dwellers suggests that they require up to date training in the use of ICT to make them achieve effectively in their farming operations.

\section{Methodology}

The sample for the study is extension agents in Delta State. The stratified sampling techniques was used to select the respondent who were made up of 34 extension agents from the ADP 21 respondents from the Ministry of Agriculture and 27 respondents from the Agricultural Units of the Local Government Areas selected from the three agricultural zones 
of the state. Questionnaire was administered to the respondents to elicit information. 88 respondents in all were used. Descriptive statistics such as frequencies and percentages were adopted in analysing the data.

\section{Results and Discussion}

Table 1: Rural Dwellers ICT (Use) Accessibility in Delta State

ITEM

1. Internet visits

$$
\text { Response }
$$

Accessible Freq. $\quad \%$

Not accessible 32

56

2. Academic information on Agriculture via ICT Accessible 28

Not accessible $\quad 60 \quad 68.20$

3. Computer Aided Instruction by extension agents

$\begin{array}{lll}\text { Accessible } & 40 & 45.50 \\ \text { Not accessible } & 48 & 54.50\end{array}$

4. Application of videos and other audio usual materials during training

$\begin{array}{lll}\text { Accessible } & 26 & 29.54 \\ \text { Not Accessible } & 62 & 70.46\end{array}$

5. Radio broadcast on Agriculture

$\begin{array}{lll}\text { Accessible } & 68 & 77.27 \\ \text { Not accessible } & 20 & 22.73\end{array}$

(Source: Field Survey 2007)

Majority (63.60\%) of the extension agents interviewed confirmed that the rural dwellers do not have access to the internet. However, only an insignificant proportion 36.40 uses it regularly or had access to internet. These findings attest to 
the claims of FAO (2000), that the update and harnessing of information is limited by the lack of trained personnel or lack of access to know how. Similarly, Boeren (1994) argues that training on extension exclude the use of ICT. The extension agents also agreed that Academic information on Agriculture via ICT is not accessible to the rural dwellers (68.20\%), while $54.46 \%$ state that the farmers are not accessible to computer aided instruction by extension agents. Also majority accede to the fact that videos and other audio-visual materials are not accessible to the rural dwellers. $77.27 \%$ of the extension agents claimed that radio broadcast on Agriculture are accessible to the rural dwellers and it is most widely used.

To emphasize the importance of ICT in rural and Agricultural transformation for increased agricultural productivity and enhanced standard of living in the rural communities, Wijekoon and Newton, (2000), argued that without appropriate grounding in communication skills and technical assets of training, programmes can quickly become ineffectual. Mohan (2001) warns that as the internet becomes the norm in commerce and information exchange in the developed world. The poorer countries will have little choice but to try to bridge the digital divide in all its forms. Since it is a known fact that information is power, it is only reasonable that rural farmers and rural dwellers as a whole will be more able to transform the rural areas if they acquire knowledge on the use of ICT for information management.

\section{Conclusion and Recommendations}

Nigeria generally and the rural areas in particular ostensibly since the early 1980 s has shown the relevance of information technology as a veritable resource in the country's quest for development technologically, economically and socially. Everywhere in the world today, Information 
Communication Technology (ICT) is regarded as a resource that is essential for the efficient and smooth transformation of the rural communities. ICT holds out clear prospects for agricultural and rural transformation if cautiously deployed. However, for efficient, meaningful and maximum exploitation of its potentials, serious thoughts and care need to be given to economic and effective design of the overall system. This is because it may be different or impossible for a computer to be used effectively if it does not form an integral part of a much wider carefully thought out system.

The belief that computers are meant for the developed countries is a misconception. Of course IT is not free, but with the kind of falling price, especially PCS even developing countries can afford and benefit from the present explosion/evolution of I.T. (Akinde and Adagunodo, 2007).

The findings generally showed that the rural farmers have very poor access to I.C.T. and they also lack the skill for its effective use. It is therefore recommended that:

1. The rural dwellers should be given the requisite skills required for information management.

2. They should be exposed to practical computer training for the enhancement of ICT use.

3. Small and cost effective systems like GSM sets and radios should be encouraged among rural dwellers especially farmers for information and training.

4. There should be a well established national ICT policy.

5. There is need to articulate appropriate national strategies on very specific targets/plans.

6. There is need to sensitize/prepare the rural farmers for appropriate use of the new technologies. 


\section{References}

Adebayo, K. (1997) Communication in Agriculture, Abeokuta: Green links International.

Adedoyin, S. F. (2004) Plentiful "Agricultural Resources. Bill Limited Audragogical Transmission." 33rd Inaugural Lecture. Olabisi Onabanyo University Ago-Iwoye, Nigeria pp.3-5.

Akinde, D.A. and Adagunodo, E.R. (2001) "Information and Communication Technology in the Administration of Colleges of Education in Kabiru, I. et al (eds) Teacher Education in the Information Technology Age. Abuja: NCCE.

Boeren, A. (1994) "In other words, the Cultural Dimension of Communication Development" CESO Report, No. 19 The Netherlands.

Mohan, Uday (2001) "Bridging the Digital Divide" in Pinstrup Anderson, P. and Pandya - Lorch, R. (Eds) The unfinished Agenda. International Food Policy Research Institute. Washington, D.C. pp.257-265.

Oladosu, I. O. (2005) "Extension Workers ICT use Characteristics and Training Needs for the Sustainability of Rural Development and Extension Training in Nigeria." Proceedings, 10th Annual National Conference (AESON) 14-17, June, 2005.

Tap Bin Sallah, D. (2004) "Rural Development in Malaysia Achievements and Challenges" Journal of Rural Development 37(2):29-47.

Wijekon, R. and Newton, B. (2000) Multimedia Support for Extension Trainers in Developing Countries. CESO Report. 20:14-18. 